Research Journal of Animal Sciences 6 (1): 8-11, 2012

ISSN: 1993-5269

(C) Medwell Journals, 2012

\title{
Morphology and Histology of Ovary's Germinal Beds in the Lacertid Lizard, Acantodactylus boskianus (Sauria; Lacertidae)
}

\author{
${ }^{1}$ Ahmad Gharzi, ${ }^{1}$ Afsaneh Yari and ${ }^{2}$ Nasrollah Rastegar-Pouyani \\ ${ }^{1}$ Department of Biology, Faculty of Science, Lorestan University, Khorram-Abad, Iran \\ ${ }^{2}$ Department of Biology, Faculty of Science, Razi University, Kermanshah, Iran
}

\begin{abstract}
In this research, researchers studied gross and microscopical characteristics of the ovaries and their germinal beds in a newly reported lizard, Acantodactylus boskianus from Iran. Researchers found that in this species ovaries show variable morphology and located under the gut, just above the kidneys. Near to gonads hilum, a single germinal bed containing numerous oogonia and developing primordial follicles is observed that seems to be derived from the epithelium's gonad. The germinal bed shaped like a butterfly in histological sections and produces a single clutch per year. It seems that this single germinal bed has evolved from merging two separate beds.
\end{abstract}

Key words: Lizard, oogonia, gravid, reproductive, microscopy, Iran

\section{INTRODUCTION}

Ovarian morphology and follicular dynamics are well known for several species of Squamata including lizards. However, these studies have shown a great interspecies inconsistency in morphological aspects between different species of lizards (Fitch, 1970; Radder and Shine, 2007). Moreover, morphological characteristics of lizard's ovaries typically vary with the stage of the annual reproductive cycle. There are also changes in the developmental stages of germ cells and in the quantity and metabolic activity of ovarian cells. The Bosc's fringe-toed lizard, Acantodactylus boskianus (Lacertidae) has recently been collected and reported from West of Iran (Rastegar-Pouyani, 2000). There is no record concerning the existence of this taxon in other regions of the Iranian Plateau and this is the reason we became interested to study this species. In lizards, the number of eggs that an ovary can produce per clutch is controlled by:

- The number of germinal beds per ovary

- The total number of follicles per germinal beds

- The proportion of follicles that become vitellogenic (Jones et al., 1982)

The germinal bed is a small region on the dorsal ovarian surface consisting of dividing oogonia, naked oocytes and primordial follicles (Klosterman, 1983; Shanbhag, 2002; Gomez and Ramirez-Pinilla, 2004). It has also been documented that there is a variation in the number of germinal beds per ovary in the Squamata including the lizards. There are species with one germinal bed such as Anolis sagrei and $A$. porcatus (Gomez and Ramirez-Pinilla, 2004), two germinal beds including Leiolopisma rhomboidalis (Wilhoft, 1963a), Sceloporus jarrovi and S. occidentalis (Goldberg, 1970, 1973) and four to six or many small scattered germinal beds as in Eumeces fasciatus and E. copei (Jones et al., 1982; Ramirez-Pinilla et al., 2002). Previous studies not only have revealed substantial interspecies variation in the number of germinal beds within lizards but also suggested broad patterns among them. To illustrate, most species with allochronic reproduction (ovulating a single egg from each ovary alternatively) and monoautochronic reproduction (ovulating a single egg from both ovaries simultaneously) seem to exhibit only one germinal bed per ovary. However, those lizards ovulate only a single egg from each ovary, possess two germinal beds per ovary (Wilhoft, 1963b) or possess one germinal bed which ovulate many eggs per ovary.

The diversity is even greater among polyautochronic lizards (those ovulate several eggs simultaneously from both ovaries). Lizards with high fecundity (large clutches and/or multiple clutches within a single breeding season) usually exhibit two germinal beds while those producing smaller clutches possess only one germinal bed (Jones et al., 1982). Due to these discrepancies in this research, researchers examine the ovarian histology and the number of germinal bed of Acantodactylus boskianus to test whether this species shows different features from other well-known species in relation to these characters or not.

Corresponding Author: Ahmad Gharzi, Department of Biology, Faculty of Science, Lorestan University, Khorram-Abad, Iran 


\section{MATERIALS AND METHODS}

Specimens of $A$. boskianus were collected from the vicinity of Harsin city $\left(34^{\circ} 17 \mathrm{~N}, 47^{\circ} 24^{\prime} \mathrm{E}\right)$, Kermanshah province, West of Iran in Spring and Summer 2010. A sample of 24 females was examined in this research. Snout-vent and tail lengths (to the nearest $0.5 \mathrm{~mm}$ ) were measured for each lizard. The largest specimen used for this research had a $60.5 \mathrm{~mm}$ snout-vent length and $115 \mathrm{~mm}$ tail length. Specimens were then euthanized with ether within 2 days of collection. The gender of each animal was determined according to morphological features and testified after dissection. The specimens were dissected and the ovaries were removed from each individual. The ovaries were immediately fixed in $10 \%$ formalin saline fixative. Tissues subsequently were dehydrated in a graded series of ethanol, cleared in xylene and embedded in paraffin. About $7 \mu$ sections were prepared by a rotary microtome and then stained with routine hematoxylineosin protocol. The sections were finally observed under a Nikon microscope equipped with a camera for photography.

\section{RESULTS AND DISCUSSION}

Morphologically, the ovaries of $A$. boskianous are paired organs, attached to the dorsal body wall through a thin mesovarium (Fig. 1A). These organs that show a sacular structure are located behind the gut and just above the kidneys. They are covered by a thin and transparent layer of peritoneal epithelium as the follicles are clearly visible within them. In Spring (May) which corresponds to gravid season, the ovaries are triangular with rough and irregular surface and display a purple color (Fig. 1B). At this time the ovaries are relatively small but the oviducts are very large and filled with huge eggs (Fig. 1A). In one specimen for example, three and two eggs were found in right and left oviducts, respectively. The largest eggs had $8.40 \mathrm{~mm}$ width and $16.89 \mathrm{~mm}$ length (Fig. 1A). In late summer (the late September) which matches with non-gravid stage, the ovaries appears round and relatively large with oocytes clearly visible from outside. Here the ovaries are white in color and have an average weight of $0.4 \mathrm{~g}$. In contrast to the ovaries, at this stage oviducts are very narrow and no eggs are seen in their lumen (Fig. 1C).

In terms of histology, the ovarian wall of $A$. boskianous is formed by the ovarian epithelium and a very thin tunica albuginea. The ovarian surface epithelium is a simple squamous and the tunica albuginea is composed of a very thin fibrous connective tissue. Follicles at different stages of development form the

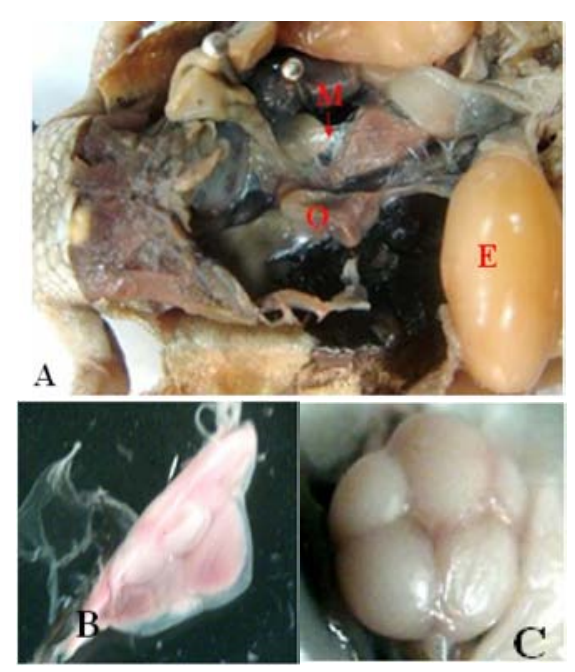

Fig. 1: Gross morphology of female reproductive system of $A$. boskianus. A) The Ovary (O) of a female in reproductively active season. Mesovarium (M) and an Egg (E) within the oviduct are also observed. B) The ovary in a gravid female in higher magnification. C) The morphology of the ovary in a non-gravid female. $\mathrm{B}$ and $\mathrm{C} \times 5$

ovarian cortex. The germinal bed is located near to the ovarian hilum and is derived from and in contact with the ovarian epithelium. Only one germinal bed is observed in each ovary. In gravid females this bed is like a butterfly with long and slender wings (Fig. 2a) whereas in nongravid females this butterfly shaped structure shows short and wide wings (Fig. 2b). Within this bed several hundreds of germinal cells may be counted. Two cellular types are distinguished among germinal cells:

- Oogonia, small germinal cells with a large and heavily stained nucleus

- Primary oocytes, larger germinal cells with a lightly stained nucleus

Compared to centrally located primary oocytes, the oogonia are compact and are seen at peripheral parts of the bed. Both types of germinal cells are surrounded by a flat layer of somatic epithelial cells (Fig. 3). This arrangement constitutes the first stage of follicular development.

In this study, researchers described some aspects of a lacertid ovarian histology observed in oviparous reptilian species. The germinal bed is the location containing oogonia that proliferate by mitotic divisions to increase the number of germ cells. It has been found that there is a variation in the number of germinal beds per 


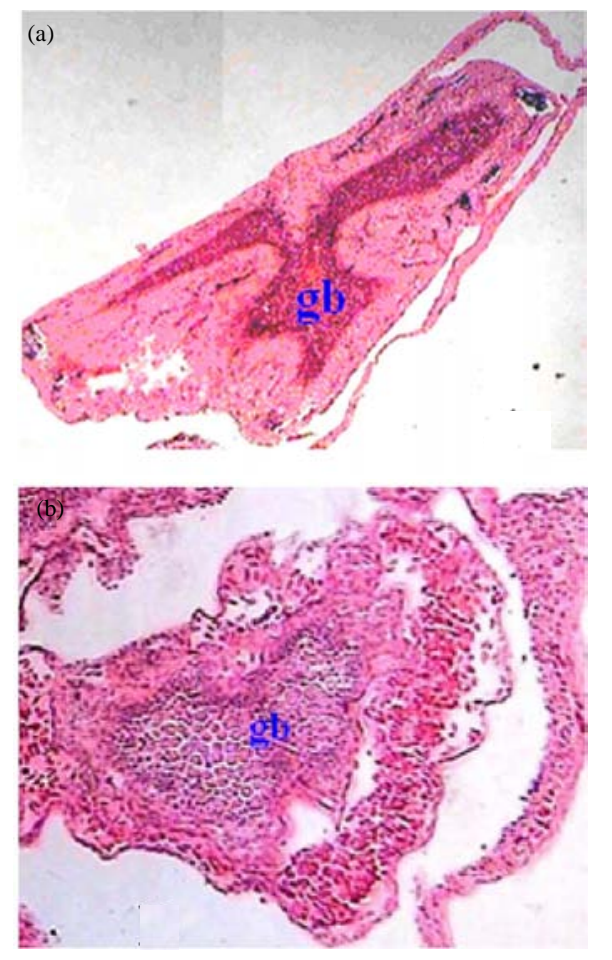

Fig. 2: The germinal bed of $A$. boskianus. a) The germinal bed of a gravid female. The bed has two long and slender wings, germinal bed (gb). b) In non gravid female, two short and broad wings are observed in this tissue. $\mathrm{H}$ and $\mathrm{E} \times 200$

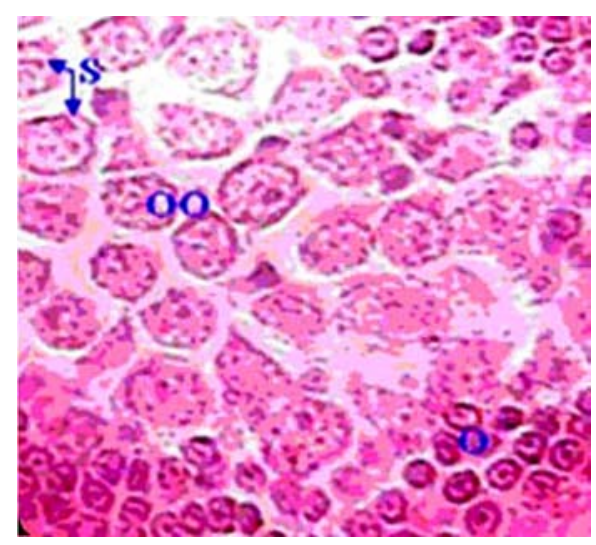

Fig. 3: Photomicrograph indicates a detailed structure of the germinal bed in A. boskianus. Oogonium (o), primary oocyte (oo), follicular cell (s). $\mathrm{H}$ and $\mathrm{E}$ $\mathrm{x} 400$

ovary in Squamata. Within the lizards, the family Scincidae shows a remarkable diversity in ovarian morphology (Gomez and Ramirez-Pinilla, 2004). To illustrate, Bassiana duperreyi exhibits only a single germinal bed per ovary (Radder and Shine, 2007). In other skinks, the number of germinal beds per ovary covers a broad range: four to six small scattered beds in Eumeces fasciatus and E. copei, two in Leiolopisma metallicum, Scincella lateralis, Carlia rhomboidalis and Mabuya longicaudata and either one or two in the viviparous Mabuya mabouya (Gomez and Ramirez-Pinilla, 2004). Further, scincid lizards appear to exhibit several unique patterns with respect to the germinal bed. For example, Eumeces has by far the highest recorded number of germinal beds per ovary among lizards and $C$. rhomboidalis possesses a perplexing condition whereby it has two germinal beds per ovary but ovulate only a single egg per ovary (Radder and Shine, 2007).

Previous studies have mainly been concentrated on lizards of the Iguanidae, Agamidae and Gekkonidae (Moodley and Wyk, 2007) and to some extent on the Scincidae but less attention has been made on lacertid species. Here, researchers showed that the lacertid lizard, Acantodactylus boskianus, like many other oviparous lizards has only a single bed per ovary. According to this fact, it means that this lizard produces just one clutch per year and displays low, fixed clutch sizes (Amey and Whittier, 2000). However, it has been suggested that single germinal bed does not exclude the possibility of occurring a second fecundity in H. mabouia and Agama atra and it may be the case for $A$. boskianus (Moodley and van Wyk, 2007).

On the other hand as researchers observed in histological pictures, the germinal bed in $A$. boskianus displays a two-segmented morphology in both gravid and non-gravid females. The presence of two-segmented single germinal bed in this species may have been resulted from a merge of the two germinal beds ovary, a condition also seen in the agamid taxa (e.g., Calotes versicolor: Jones et al., 1982). This merging process has also been suggested for the single germinal bed of Agama agama (Radder and Shine, 2007).

In general, it is believed that the oviparous lizards with two or more germinal beds are associated with high fecundity (large and/or multiple clutches per season) whereas species with one germinal bed per ovary display low, fixed clutch sizes (Jones et al., 1982). Nonetheless, it has been documented that at least one species with a single germinal bed (Agama agama) produces $>1$ egg (1-6 eggs) per ovary, showing that moderately large and variable clutch sizes can be produced from a single germinal bed (Jones et al., 1982). In agreement with this proposition in the present study we observed that this Acanthodactylus boskianus occurs in higher frequency in its niche as it is comparable to Ophisops elegans which is the most frequent species in the studied region. In 
contrast to $A$. boskianus, Laudakia nupta which seems to be a lizard with a single germinal bed in its ovaries is found in very low number in this locality. Therefore, researchers assume that there is no clear relation between the number of germinal beds and fecundity of lizards.

Another factor which is related to regulation of clutch size is the number of germinal cells in each germinal bed. Although, researchers did not count this number in current research, there are evidence that the species with higher number of germinal cells in their germinal beds show a higher instantaneous fecundity (Jones et al., 1982). However, it is not clear whether this is true for all lizards and squamata in general.

\section{CONCLUSION}

While in the current study we presented some histological aspects of ovary in A. boskianus, many other characters of this organ still remains enigmatic and further research on different reptilian types may in the future reveal the secrets of a very interesting ovarian component.

\section{ACKNOWLEDGEMENT}

Researchers would like to thank all members of Biology Department, Lorestan University for their technical supports during the course of doing this research.

\section{REFERENCES}

Amey, A.P. and J.M. Whittier, 2000. The annual reproductive cycle and sperm storage in the bearded dragon, Pogona barbata. Aust. J. Zool., 48: 411-419.

Fitch, H.S., 1970. Reproductive cycles in lizards and snakes. Univ. Kansas Mus. Nat. Hist. Misc. Publ., 52: 1-247.
Goldberg, S.R., 1970. Seasonal ovarian histology of the ovoviviparous iguanid lizard Sceloporus jarrovi cope. J. Morphol., 132: 265-275.

Goldberg, S.R., 1973. Ovarian cycle of the Western fence lizard, Sceloporous occidentalis. Herpatologica, 29: 284-289.

Gomez, D. and M.P. Ramirez-Pinilla, 2004. Ovarian histology of the placentotrophic Mabuya mabouya (Squamata, Scincidae). J. Morphol., 259: 90-105.

Jones, R.E., T. Swain, L.J. Guillette Jr. and K.T. Fitzgerald, 1982. The comparative anatomy of lizard ovaries, with emphasis on the number of germinal beds. J. Herpetol., 16: 240-252.

Klosterman, L.L., 1983. The ultrastructure of germinal beds in the ovary of Gerrhonotus coeruleus (Reptilia: Anguidae). J. Morphol., 178: 247-265.

Moodley, G.K. and J.H.V. Wyk, 2007. Folliculogenesis and ovarian histology of the oviparous gecko, Hemidactylus mabouia (Sauria: Gekkonidae). Afr. J. Herpetol., 56: 115-135.

Radder, R. and R. Shine, 2007. Germinal bed condition in a polyautochronic single-clutched lizard, Bassiana duperreyi(Scincidae). Amphibia-Reptilia, 28: 159-162.

Ramirez-Pinilla, M.P., V.H. Serrano and J.C. Galeano, 2002. Annual reproductive activity of Mabuya mabouya (Squamata, Scincidae). J. Herpetol., 36: 667-677.

Rastegar-Pouyani, N., 2000. First record of the lacertide Acanthodactylus boskianus (Sauria: Lacertidae) for Iran. Asiatic Herpetol. Res., 8: 65-80.

Shanbhag, B., 2002. Reproductive biology of Indian reptiles. Proc. Indian Natl. Sci. Acad., 68: 497- 528.

Wilhoft, D.C., 1963a. Gonadal histology and seasonal changes in the tropical Australian lizard Heiolopima rhomboidalis. J. Morphol., 113: 185-204.

Wilhoft, D.C., 1963b. Reproduction in the tropical Australian skink, Leiolopisma rhomboidalis. Am. Midland Nat., 70: 442-461. 